Size structure of rumen bacterial populations.

\begin{tabular}{llllll}
\hline Digesta from: & Date of sampling & \multicolumn{1}{c}{$b^{l}$} & se & rsd & $r^{2}$ \\
\hline Grazing sheep & October & $-2.75 \mathrm{ab}$ & 0.105 & 0.036 & 0.966 \\
Grazing kangaroos & October & $-2.77 \mathrm{a}$ & 0.058 & 0.011 & 0.990 \\
Grazing kangaroos & November & -2.41 & 0.034 & 0.004 & 0.995 \\
Pen-fed sheep & December & $-3.00 \mathrm{~b}$ & 0.073 & 0.018 & 0.986 \\
\hline
\end{tabular}

${ }^{1}$ Values followed by the same letter are similar $(p>0.05)$, indicating similar size structures.

3. Baker SK, Dehority BA, Chamberlain NL, Purser DB (1995) Annal Zootech 44, Supplément, 143

4. Dehority BA (1996) J Euk Microbiol 43, 285-95

\section{ANAEROBIC FUNGI}

Molecular approaches to the characterisation and differentiation of the anaerobic gut fungi. $J \mathrm{~L}$ Brookman ${ }^{1,2}, \mathrm{G}$ Mennin ${ }^{1,2}$, S Rogers ${ }^{1,2}$, APJ Trinci ${ }^{1}$, MK Theodorou ${ }^{2}$ 'School of Biological Sciences, Stopford Building, University of Manchester, Manchester MI3 9PT, UK.; ${ }^{2}$ Institute of Grassland and Environmental Research, Plas Gogerddan, Aberystwyth, Dyfed. SY23 3EB, UK)

Anaerobic fungi within the digestive tract of ruminants play an important role in the degradation of structural plant polysaccharides ingested by the host animal. Since their discovery, several different approaches have been adopted to isolate and characterise a variety of different fungal isolates. The fungi have been placed within the class Chytridiomycetes and assigned their own order Neocallimastigales which contains a single family the Neocallimastigaceae. To date, five genera have been described within the Neocallimastigaceae, as follows: Anaeromyces, Caeco- myces, Neocallimastix, Orpinomyces and Piromyces. The designation of a genus is largely dependent upon morphological characteristics, such as the number of zoosporangia per thallus (i.e. one zoosporangium for a monocentric thallus or many zoosporangia for a polycentric thallus) and the number of flagella present on the uni-, bi- or multi-flagellated zoospore, whereas assignment at the species level is by zoospore ultrastructure. In addition to these classical taxonomic approaches, gut fungi have also been investigated using a variety of physiological, biochemical and (more recently) molecular techniques.

We have used the ribosomal ITS1 DNA sequence as a phylogenetic tool for comparing a variety of fungal isolates obtained from different host animals in widely-different geographical locations to assess the relatedness within and between different gut fungal genera. The ribosomal ITS1 sequence has been amplified from 22 different isolates spanning the Neocallimastigaceae family. The DNA sequence of this region has been determined and, together with other published sequences, used to construct a phylogenetic analysis of the order. Analysis of these ITS1 DNA sequences has enabled the production of a series of genera- and species-specific probes. These probes have then been used to develop membrane-based assays for the 
detection and differentiation of the anaerobic gut fungi. We have also developed a chitin synthase gene marker for both phylogenetic and hybridisation studies.

A comparison of the effectiveness of both these gene sequences for the phylogenetic studies and the hybridisation-based differentiation of the various anaerobic fungal genera will be discussed. The potential for further development of these molecular approaches to the characterisation of the anaerobic gut fungi will be considered. In particular, the use of hybridisation-based assays for the direct detection, enumeration and differentiation of anaerobic gut fungal zoospores in rumen fluid and gut fungal thalli attached to plant biomass in rumen digesta will be discussed.

Grouping of anaerobic fungi isolated from the digestive tract of herbivores by PCR-RFLP analysis of ITS. V Julliand ${ }^{1}, M$ Hosny ${ }^{1}, \mathrm{H}$ Dulien, ${ }^{1}, \mathrm{G}$ Fonty ${ }^{2}$ (INRA-ENESAD, Laboratoire de Microbiologie Anaérobie, BP 1607, 21036 Dijon, France; ${ }^{2} I N R A$, Laboratoire de Microbiologie, CR Clermont FerrandTheix, 63122 Saint-Genès-Champanelle, France)

The anaerobic fungi Piromonas communis and $P$. citronii are natural inhabitants of the rumen of ruminants and of the caecum of equids, respectively, These two species are usually differentiated by their morphological and metabolic characteristics [1]. In this study the PCR-RFLP analysis of the intergenic transcribed spacers (ITS) of the ribosomal RNA gene was used to discriminate between closely related strains isolated from the digestive tract of herbivores.

Seven strains of $P$. citronii, isolated from the ass caecum $\left(A_{2}, A_{3}, A_{4}, A_{5}\right)$ and from the pony caecum $\left(\mathrm{P}_{2}, \mathrm{P}_{3}, \mathrm{P}_{4}\right)$ were compared to three ruminal strain of $P$. communis, isolated from a cow $\left(\mathrm{V}_{1}, \mathrm{~V}_{2}\right)$ and from a sheep $\left(\mathrm{M}_{1}\right)$. After extraction and purification of DNA from each strain, the ITS of the ribosomal unit together with the $5.8 \mathrm{~S}$ gene were specifically amplified by PCR using the universal primers ITS1 and ITS4. Amplification products were then digested by 13 restriction endonucleases (RFLP). The length of the amplified fragments was the same for all strains $(720 \mathrm{Kpb})$ except for $\mathrm{A}_{5}(780 \mathrm{Kpb})$ and $\mathrm{M}_{1}(770 \mathrm{Kpb})$. Five enzymes $(A l u \mathrm{I}$, EcoRI, NdeI, Hind III and HaeIII) did not cut the ITS. TaqI yielded three fragments $(340,180$ and $140 \mathrm{bp})$ after digestion of the ITS region of the equine strains and only two ( 370 and $320 \mathrm{bp}$ ) or one ( 370 bp) from the ITS of the ruminal $P$. communis strains. Rsal generated one fragment (650 bp), and two (640 and $615 \mathrm{pb})$ from the ITS of $P$. citronii. Hinfl yielded one fragment of $360 \mathrm{bp}$ from the ITS of the two ruminal bovine strains and one $(380 \mathrm{bp})$ from the ITS of the ruminal ovine strain. MseI, Sau3a, Mbol, NdeII and TaqI also discriminated the bovine strains from the ovine strain by the number of the length of fragments yielded. HinfI, MseI, RsaI, Sau3a, MboI, NdeII and DdeI discriminated $A_{s}$ from the other six equine strains. For example, MseI generated one fragment of $280 \mathrm{bp}$ from $A_{s}$ and two fragments $(220$ and $85 \mathrm{pb})$ from $\mathrm{A}_{2}, \mathrm{~A}_{3}$, $\mathrm{A}_{4}, \mathrm{P}_{2}$ and $\mathrm{P}_{4}$. Among the $P$. citronii strains, two groups were discriminated by Hinfl which yielded three fragments (360, 250 and $150 \mathrm{bp}$ ) from $A_{2}, A_{3}, A_{4}, P_{2}$ and only one ( $360 \mathrm{bp}$ ) from $\mathrm{P}_{3}$ and $\mathrm{P}_{4}$. MseI 